and communicated telegraphically by Prof. E. C. Pickering :-

$$
\begin{aligned}
& T=1908 \text { August } 25^{\circ} 72 \\
& \infty=51^{\circ} 9^{\prime} \text { l } \\
& 8=236^{\circ} \text { I } 2^{\prime}{ }^{\prime} \text { I908. } \\
& i=145^{\circ} 48^{\prime} \text { ) } \\
& q=0.103 \\
& e=0.4395 \\
& \text { Period }=\mathbf{2}^{\mathrm{a} \cdot} \cdot 55 \text {. }
\end{aligned}
$$

Osculation, I908 March 8, igh. $45.5 \mathrm{~m}$. G.M.T.

Search-ephemerides ror Comet Tempel ${ }_{3}$-Swift.-Three ephemerides for the comet discovered by Tempel in 1869 , and recognised as periodical by Swift in 1880 , are published by M. E. Maubant in No. 4260 of the Astronomische Nachrichten (p. 349, August 14). These ephemerides give the positions of the comet from August 29 to November I, the times of perihelion being taken as September 22.88, September 30.88, and October 8.88 respectively. The following is an extract from the ephemeris for the mean date :-

$$
\begin{aligned}
& \begin{array}{cccc} 
& \text { Ephemeris (12h. M.T. Paris). } & \\
& 908 & \log r & \log \Delta
\end{array}
\end{aligned}
$$

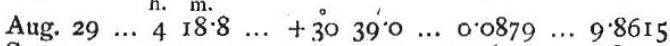

$$
\begin{aligned}
& \text { Sept. } 2 \ldots 4400^{\circ} \ldots+31 \quad 27.9 \ldots 0.0 \$ 22 \ldots .9 .8542 \\
& \begin{array}{lllllllllllll} 
& 6 & \ldots & 5 & 1.5 & \ldots & +32 & 3.5 & \ldots & 0.0771 & \ldots & 9.8484
\end{array}
\end{aligned}
$$

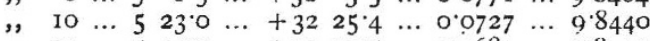

$$
\begin{aligned}
& \begin{array}{llllllllllllllllll}
\prime \prime & 14 & \ldots & 5 & 44.3 & \ldots & +32 & 33.5 & \ldots & 0 & 0689 & \ldots & 9 & 8409
\end{array}
\end{aligned}
$$

From this ephemeris it is seen that the comet is travelling eastwards through Taurus to Auriga, and may be discovered during the early morning before dawn. Its period is about $5^{\frac{1}{2}}$ years, and it was well observed in I89r, although at its more recent returns in $x 897$ and 1903 it was not seen. On September 9 the comet should be about $4^{\circ} \mathrm{N}$. of $\beta$ Tauri, which rises about ro p.m.

Definttive Orbit of Comet i 826 V.-No. 4269 of the Astronomische Nachrichten (p. 34I, August i4) contains a discussion, by Herr A. Hnatek, of Vienna, of the orbit of comet $1826 \mathrm{~V}$, from which the author deduces that the orbit was parabolic, the most probable ellipse giving a period of nearly 28 , 000 years. Herr Hnatek directs attention to the fact that in the early hours of November I8, 1826 , the comet grazed the sun.

Relative Depths of the Sun-spots of a Group.-Discussing stereocomparator measures which he has made on photographs taken at Greenwich on July 4,5 , and 6 , Prof. Wilhelm Krebs, in No. 4267 of the Astronomische Nachrichten (p. 315, August 7), shows that the different spots of the group which was then near the central meridian were at different levels, and also that the changes of level varied from spot to spot during the intervals between the taking of the photographs. Whilst the most easterly spot showed a sharp increase of height above the datum line, the most westerly exhibited a sharp fall. The different heights, measured in $1000 \mathrm{~km}$., varied from 137 to -3 , whilst the general increase in height during the two intervals amounted to $17,000 \mathrm{~km}$., or 27 per cent.

\section{AN ALLEGED EXCRETION OF TOXIC SUBSTANCES BY PLANT ROOTS.}

THE idea formulated a century ago by de Candolle that plant roots excrete toxic substances has recently been very much pushed forward by the American Bureau of Soils to explain the effects of fertilisers and the advantage of a rotation of crops. The American method of experiment is to grow seedlings in water culture for a few days and measure the amount of transpiration, which is considered to be an index of the amount of growth. The seedlings are then removed and replaced by a second

1 (a) "Fertility of Soils as affected by Manures." By Frank D. Gardner. (U.S. Department of Agriculture, Bulletin No. 48.)

(b) "Note on a Toxic Substance Excreted by the Roots of Plants." B By F. Fletcher. (Memoirs of the Department of Agriculture in India, vol. ii., No. 3.)

$(c)$ "Crop Rotation and Soil Exhaustion." Scientific Journal, vol. ii., No. 19.)

By F. Fletcher. (Cairo NO. 2026, vOL. 78$]$ batch, without changing the water; the rate of transpiration is found to be diminished, showing (it is stated) that a toxic body excreted by the roots of the first batch is adversely affecting the second. Further, seedlings grown in an aqueous extract of certain poor soils are found to transpire less water than others grown in distilled water, and it is concluded that these soils contain some toxic material, presumably excreted by plants. The toxic body is, however, precipitated on addition of charcoal, ferric hydrate, and solutions of various manures; and the Bureau of Soils argues that the function of fertilisers, in some cases at any rate, is not to feed the plant, but to precipitate the toxin excreted by previous plants. Rotations of crops are of advantage, because the toxin excreted by one plant is not necessarily harmful to plants of a different order.

It cannot be said that any very convincing evidence is offered in support of this view. The assumption that transpiration is a measure of plant growth is not borne out by any of the figures quoted; thus in a series of experiments given in Bulletin No. 36 the crop weights and transpiration results are :-

\begin{tabular}{l|c|c|c|c|c|c|c|c|c}
\hline Experiment & I & 2 & 3 & 4 & 5 & 6 & 7 & 8 & 9 \\
$\begin{array}{l}\text { Transpiration } \\
\text { Crop weight }\end{array}$ & 100 & 126 & 116 & 107 & 116 & 133 & 119 & 147 & 111 \\
& 108 & 95 & 100 & 103 & 112 & 107 & 129 & 108
\end{tabular}

Another weak point is that the experiments are made with seedlings, and last only a few days, instead of being carried on to the end of the plant's life. The nutrition of the seedling is not the same as that of the plant, and even if it were demonstrated that secretion from seedling roots took place, it would not follow that there was a similar secretion from the roots of fully grown plants.

In the last Bulletin from the Soil Bureau (No. 48) an account is given of more than 13,000 pot trials with soils from different parts of the United States. The results show, as might be expected, that addition of manures increases the crop, and that each manurial substance exerts a specific effect which is not shown by any other; with this statement everyone would agree. The further conclusion is drawn that the character of fertiliser required depends more upon local conditions and practices than on the type of soil or the geological formation to which it belongs, so that the fertilisers required for the same type of soil as it occurs in different localities usually vary more than those required for very different types when in the same locality and subjected to similar environment. If this generalisation turned out to be true, it would be more easy to reconcile with the plant excretion view than with the nutrition view of the function of fertilisers, but an examination of the tables does not show that there is any proof. Averages are taken without any regard to their probable value. Thus in one section of the table we find thrce soils only, and they give the following percentage increases when treated with various manures, yet the author finds no difficulty in taking an average:-

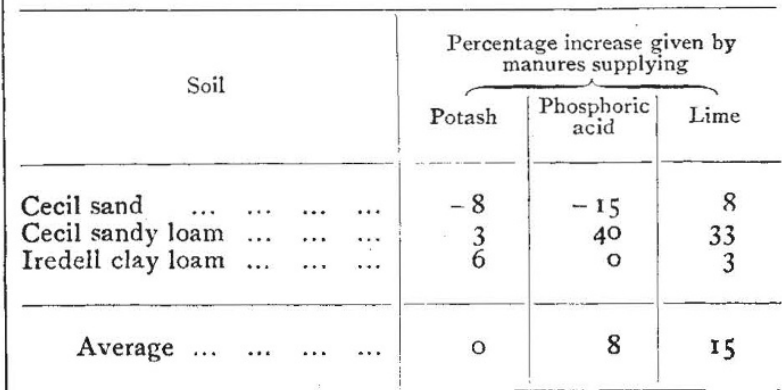

The magnitude of the experimental error can only be inferred from one table, where the separate crop weights for twenty pots are given; it would appear to be considerable, since the weights vary from 58.7 grams to 89.9 grams; but the author groups the pots in sets of five, and in this way reduces the error to 5 per cent., which is given as the probable error for all the experiments! There 
would be no particular difficulty in maintaining any thesis if results could be treated in this way.

Mr. Fletcher's work has been partly on the above lines. $\mathrm{He}$ obtained a "solution of excreta" by growing plants in water culture, and then used this solution as a medium for plant growth. It proved to be toxic, and the conclusion is drawn that the plant first used excreted some poisonous body. The experiment, however, is not a very good one. It is well known by those who have worked with water cultures that bacterial decompositions are liable to take place in the solution, producing substances injurious to plants; precautions always have to be taken to prevent development of bacteria. It does not appear that any such precautions were taken by $\mathrm{Mr}$. Fletcher, indeed, the conditions under which he worked seem to have been favourable to bacterial development; well water was used, and the "solution of excreta" was allowed to evaporate at ordinary temperature until sufficiently concentrated for the second part of the experiment. There is no evidence that the toxic substance was excreted by the plant; it might equally well have been a bacterial product.

In another set of experiments crops were grown in rows side by side, and three lots of measurements were taken :(I) the yield in the outside row, bordering on the bare ground; (2) the yield in the middle row; (3) the yield in a row bordering on another crop. The first is the highest, the second shows the effect of the plant on others of the same kind, and the third shows the effect on others of a different kind. The falling off in yield in the second and third cases is regarded by $\mathrm{Mr}$. Fletcher as proof of a toxic excretion; it is generally explained as due to lack of water or food, and no satisfactory evidence is adduced against this view; indeed, Mr. Fletcher states that the reductions in crop are less marked under a more evenly distributed rainfall. We cannot consider that the question of root excretion has been materially advanced in any of these publications.

E. J. R.

\section{ACID-RESISTING ALLOYS.}

A PAPER was read at a recent meeting of the Faraday Society by Mr. Ad. Jouve describing the remarkable resistive character of ferro-silicon and other silicon alloys. Attention was directed to the fact well known to analysts that no methods of analysis for this substance, based upon the use of acids, with the exception of hydrofluoric acid, are employed for ferro-silicons, because ferro-silicon containing more than 20 per cent. of silicon is insoluble in acids. This protective property of metalloid is being made use of in producing acid-resisting vessels. Ferro-silicons, however, are not the only substances which possess this property; almost any alloy of a metal with this metalloid will behave in the same way to a greater or lesser degree, according to the nature of the metal. Calcium-silicide is, for example, unaffected by acid, whereas calcium itself acts vigorously upon water.

As showing the resistance of these alloys, which are called " Métillures," to acids, the following example is interesting:- Nitric acid, even as a vapour such as is obtained at the exit of a bisulphate retort or when mixed with nitrous acid, does not affect them at all. A striking example of this is given by a pipe which has been submitted for nearly five years to the daily passage of $660 \mathrm{lb}$. of nitric acid vapour at temperatures varying from $150^{\circ}$ to $200^{\circ} \mathrm{C}$. without its loss in weight exceeding a few decigrams in a total weight of a score of kilograms. This loss occurred quite at the beginning of the period, and was probably due to a few impurities remaining on the inner surface of the pipe after fusion.

Sulphuric and hydrochloric acid appear to have still less effect, and pipes of ferro-silicon have been used for carrying and condensing gaseous hydrochloric acid. Acetic acid and the mixture produced by treating calcium acetate are also without action. Seeing the extremely high price of platinum, which is the most stable of all industrial metals, it would appear probable that the advent of these new resisting alloys will become of very considerable importance. The chief drawback to their use is in the brittleness and weight of the alloy, the vessels made of it being generally rather thick.

\section{CERTAIN ASPECTS OF THE WORK OF LORD KELVIN. ${ }^{1}$}

WHEN a man of the first magnitude works continually at a single group of subjects from an age preceding twenty to an age exceeding eighty, the circumstance is so exceptional and the output so enormous that no ordinary summary or criticism can do it justice.

I shall not aim at any chronological sequence, and, in fact, propose to begin with those later physico-philosophic views which seemed to determine the direction of his thoughts and the attitude of his mind to nascent and contemporary discoveries in recent years.

For this aspect, even if difficult to treat of, is one which a biographer is bound in some fashion or another not to shirk; and, although myself unable to regard it with full sympathy, I am confident that my point of view is neither presumptuous nor disrespectful.

\section{Kinetrc Theory of Solidity.}

Now, I confess that for some years before his death Lord Kelvin's attitude to fundamental physical or philosophical questions was somewhat of a puzzle to me. He seemed to be abandoning ground which he himself had opened up to explorers, and discouraging others from advancing in directions where he himself had pioneered. As a matter of fact, I was uncertain whether his position was even consistent and logically tenable or not; and at the British Association meeting at Leicester, during a discussion on the constitution of the atom in Section A, I had an opportunity of respectfully and deferentially challenging him on this subject. He responded, as always, in the kindest manner, and with great and almost exceptional lucidity indicated what had now become his position. I would not be understood as implying that he carried conviction, or led me to regard that position as a desirable one to occupy; but he showed it to be a consistent and logical one, which he had every right to occupy if he chose, and on which, therefore, it must be left for posterity, or at least for effluxion of time and progress of discovery, to pass anything in the nature of ultimate judgment.

I was much interested in this pronouncement, and before leaving Leicester jotted down a few notes concerning it, with the view of publishing them in his lifetime, in order that he might, if he chose, add to, or subtract from, or modify the statement. Other things prevented rapid publication, however, and accordingly it is too late for one of the objects in view, but still the notes are worth publication as suggesting genuine antithetical or alternative views of the universe. (They have now appeared in NATURE for July 2, 1908.)

It may seem as if the real antithesis was between the postulates of a connecting medium, on the one hand, and of action at a distance across empty space, on the other, and as if Lord Kelvin were in favour of the latter view. I do not, however, think it would be fair to attach to him that responsibility. I think it was more a matter of practical politics, with him, than a philosophical conception. I think he would have liked to see an explanation in terms of a connecting medium, if it could have been managed; but, after spending some years in the attempt, he abandoned it either as too difficult or as hopeless, and constrained himself to be satisfied with unexplained forces between masses of matter acting according to specified laws; the question of the medium or mechanism through which they acted being left out of account as unnecessary from the point of view of practical dynamical calculation and consistent reasoning.

He did speak at times, however, as if immediate action across empty space would be logically satisfactory to him, and quite good enough as an explanation; the only question being, was it the true one? To me I confess that any such philosophic scheme must necessarily be a cold and merely descriptive account of material activity-that it must necessarily fail to go to the heart of the matter or to constitute what may more reasonably be called " explanation." The conception of forces acting according to a specified law of distance is capable of yielding dynamical results truly, but not of explaining them. Ex-

1 Abridged from the presidential address to the Faraday Society, delivered by Sir Oliver Lodge, F.R.S., on May 26. 